\title{
Pendidikan Kesehatan Gizi Seimbang pada Balita
}

\author{
Suci Utami, Rosmalia Kamil, Dea Riskha Fitriliana \\ E mail: deandrahangkoso@gmail.com \\ Prodi Kebidanan DIII, Sekolah Tinggi Ilmu Kesehatan Brebes, Indonesia \\ Jalan Raya Jatibarang Km 8 Janegara Jatibarang Brebes
}

Telp/fax. (0283) 6712288

\begin{abstract}
Abstrak
Pendidikan kesehatan merupakan kegiatan memberikan dan meningkatkan pengetahuan, sikap baik individu, kelompok atau masyarakat untuk memelihara dan meningkatkan kesehatan mereka sendiri Pendidikan kesehatan tentang gizi seimbang pada balita dapat memberikan pengetahuan lebih tentang Gizi pada orang tua agar dapat mencegah gizi buruk pada balita Secara umum gizi buruk merupakan masalah kesehatan yang dapat mempengaruhi tumbu $\mathrm{h}$ kembang anak hingga dewasa, untuk itu sangat penting bagi orang tua memahami bahaya gizi buruk dan cara menceganya dengan memberikan makanan gizi seimbang. Metode dalampelaksanaan Ibm dilakukan dengan metode ceramah, dan disksi dengan menggunakan lealetadapun luaran yang diperoleh yaitu meningkatnya kesadaran dan pengetauan orang tua tentang gizi seimbang untuk balita di Desa Sutapranan. Luaran yang diperoleh yaitu adanya media pendidikan kesehatan tentang gizi seimbang pada kegiatan PKK di Desa Sutapranan.
\end{abstract}

Kata Kunci: pendidikan kesehatan; gizi seimbang; balita.

\begin{abstract}
Health education is an activity to provide and increase knowledge, good individual, group or community attitudes to maintain and improve their own health Health education on balanced nutrition in toddlers can provide more knowledge about nutrition to parents in order to prevent malnutrition in children under five is a health problem that can affect child development to adulthood, it is very important for parents to understand the dangers of malnutrition and how to prevent it by providing a balanced nutritional diet. The method of implementing Ibm is carried out by the lecture method, and the discussion using lealets while the outcome obtained is the increased awareness and knowledge of parents about balanced nutrition for toddlers in Sutapranan Village. The output obtained was the presence of health education media on balanced nutrition in PKK activities in Sutapranan Village.
\end{abstract}

Keyword: health education; balanced nutricion; todller.

\section{Pendahuluan}

$\begin{array}{lr}\text { Pembangunan } & \text { Nasional } \\ \text { bertujuan meningkatkan } & \text { warga } \\ \text { kesejahteraan seluruh } & \text { andak } \\ \text { Indonesia, dimana salah satu tolak } \\ \text { ukur keberasilannnya adalah } \\ \text { tercapainya status gizi masyarakat } \\ \text { yang optimal untuk meningkatkan } \\ \text { kualitas sumber daya manusia. } \\ \text { Pembangunan pangan dan gizi } \\ \text { memiliki cakupan yang luas mulai }\end{array}$

dari aspek produksi pangan distribusi konsumsi yang dapat mempengaruhi status gizi. Berdasarkan data dari Dinas Kesehatan Provinsi Jawa Tengah kasus balita gizi buruk di Kabupaten Tegal tahun 2018 masih tinggi yaitu sebanyak 51 kasus[1].

Gizi buruk dapat dicegah dengan meningkatkan pemahaman tentang gizi seimbang pada balita 
salah satu cara untuk meningkatkan pemahaman orang tua adalah dengan memberikan pendidikan kesehatan. Sejalan dengan penelitian yang dilakukan oleh Hariska Pratiwi [2]yang menyatakan bawa terjadi peningkatan pengetahuan pada orang tua setelah diberikan konseling tentang gizi balita melalui metode konseling gizi di Wilayah Kerja Wua-Wua Kota Kendari Taun 2016.

Hal ini mendorong kami untuk melakukan pengabdian kepada masyarakat tentang pemberian pendidikan kesehatan tentang gizi seimbang pada balita di Desa Sutapranan Kecamatan Dukuturi Kabupaten Tegal sehingga orang tua dapat memberikan gizi yang tepat pada balita dan dapat mencega teradinya gii buruk

\section{Metode}

Pelaksanaan pengabdian pada masyarakat (IbM) dilakukan dengan metode ceramah dan diskusi dengan media leafleat. Tahapan dalam kegiatan ini adalah persiapan program IbM dalam bentuk survey pada kelompok sasaran, koordinasi dan pengurusan ijin dengan instansi terkait (desa), persiapan media konseling dal sarana prasarana, tahapan selanjutnya yaitu pelaksanaan kegiatan pemberian pendidikan kesehatan tentang gizi seimbang dengan metode diskusi dan Tanya jawab dengan menggunakan media leaflet taapan terakhir yaitu melakukan follow up kegiatan tersebut.

\section{Hasil dan Pembahasan}

Kegiatan IbM ini telah dilaksanakan di Desa Sutapranan Kecamatan Dukuhturi Kabupaten Tegal yang bertempat di Ka PKK desa Sutapranan pada hari minggu tanggal 18 oktober 2020 dengan jumlah perserta 26 orang. Para peserta adalah orang tua yang memiliki balita, mereka sangat antusias mengikuti kegiatan pendidikan kesehatan tentang Gizi seimbang pada balita.

Kegiatan IbM ini diawali dengan koordinasi denga ketua Pkk desa sutapranan untuk mengundang orang tua yang memiliki balita pada tanggal 18 oktober 2020 pada saat pelaksanaan diawali dengan pendaftaran peserta yang hadir serta peserta diberikan pertanyaan seputar pengetahuan gizi seimbang pada balita.

Sebelum dilakukan pendidikan kesehatan tentang gizi seimbang pada balita orang tua diberikan beberapa pertanyaan dengan jumlah 10 pertanyaan tentang gizi seimbang pada balita, 40 persen orang tua belum tahu kandungan gizi pada bahan pokok makanan dan bahaya gizi buruk pada balita. Pemberian pendidikan kesehatan tentang Gizi balita pada orang tua dilaksanakan selama 60 menit dengan metode diskusi dan tanya jawab dimana orang tua sangat antusias mendengarkan dan mengajukan beberapa pertanyaan diantara nya tentang gizi yang baik, menu seimbang serta pengolahan makanan yang benar dan bahaya balita dengan kekurangan gizi. 
Gambar. Pemberian pendidikan kesehatan tentang Gizi balita pada orang tua
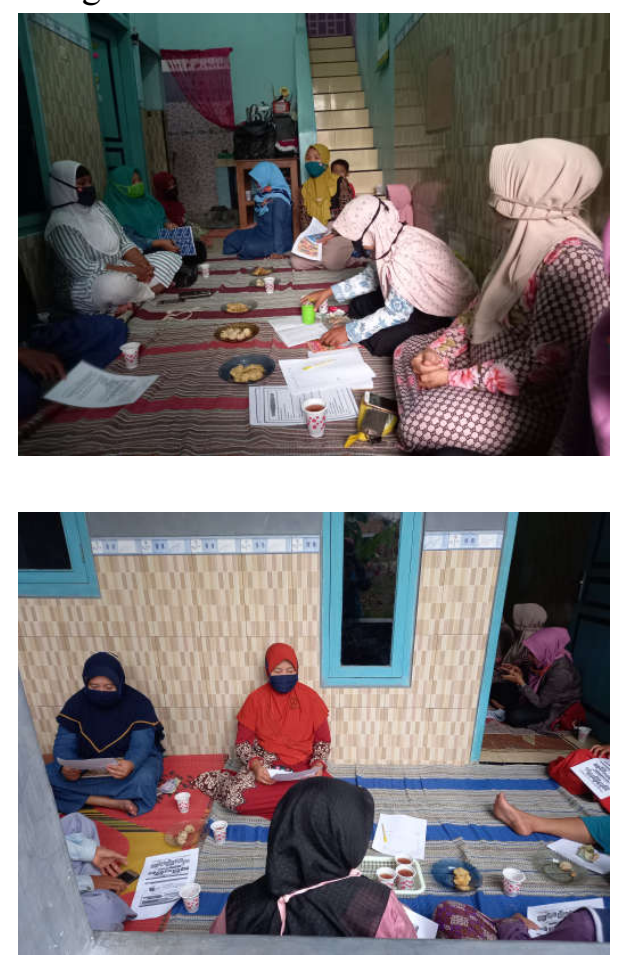

Setelah diberikan pendidikan kesehatan tentang gizi seimbang[3] serta tanya jawab dilakukan kembali evaluasi, hasilnya ibu mengerti dan memahami gizi seimbang pada balita, bagaimana cara mengolah makanan yang baik dan mencehag gizi buruk pada balita dengan memberikan menu seimbang pada balita.

Pernyataan tersebut sejalan dengan amico ar.et.all., dalam Apri Sulistyaningsih[4] yang menjelaskan bahwa membentuk perilaku sehat melalui informasi, motivasi dan peningkatan ketrampilan terbukti efektif, dimana tujuan memberikan pendidikan kesehatan yaitu terjadinya perubahan perilaku sehat sesuai konsep hidup sehat baik fisik, mental dan sosial.

\section{Kesimpulan}

Berdasarkan hasil pelaksanaan IbM yang telah dilakukan di Desa Sutapranan dengan peserta sebanyak 26 orang tua yang memiliki balita, terdapat peningkatan pengetahuan yang signifikan setelah diberikan pendidikan kesehatan dengan media leaflet. Diperlukan dukungan dari suami dan keluarga untuk mendukung ibu agar dapat memenuhi kebutuhan gizi pada balita mereka, sehingga balita tidak mengalami gizi buruk.

\section{Daftar Pustaka}

[1]

Gubernur Jawa Tengah Nomor 61 Tahun 2019. vol. 87. pp. 149-200, 2019.

[2] Pratiwi H, Bahar H, Rasma. Peningkatan Pengetahuan, Sikap, Dan Tindakan Ibu Dalam Upaya Pencegahan Gizi Buruk Pada Balita Melalui Metode Konseling Gizi Di Wilayah Kerja Puskesmas Wua-Wua Kota Kendari Tahun 2016. :Jurmal Ilm Mhs Kesehat Masy. vol. 1, no.3, pp. 1-8, 2016. [Online].: http://betterwork.org/inlabourguide/wpcontent/uploads/permenaker08-2010alat_pelindung_diri.pdf

[3] Kemenkes RI. (2019). Apa saja sepuluh pedoman gizi seimbang?. [Online]. http://p2ptm.kemkes.go.id/info graphic-p2ptm/obesitas/apasaja-sepuluh-pedoman-giziseimbang 
[4] Sulistianingsih A. Pengaruh Pendidikan Kesehatan Nutrisi dengan Anemia pada Kehamilan Berdasarkan Information Motivation Behavior Skill (IMB) Model. 1st ed. Lampung: Rumah kayu Pustaka Utama, 2020. 